\title{
EDITORIAL
}

\section{LA REVISTA ESPÃ̃OLA DE SALUD PÚBLICA EN LA BIBLIOTECA VIRTUAL SciELO}

\author{
«... En el mapa de tu imperio, oh Gran Jan, deben encontrar su sitio \\ tanto la gran Fedora de piedra como las pequeñas Fedoras de las esferas \\ de vidrio. No porque todas sean igualmente reales, sino porque todas son \\ sólo supuestas. La una encierra lo que se acepta como necesario cuando \\ todavia no lo es; las otras lo que se imagina como posible y un minuto \\ después dejan de serlo»
}

Italo Calvino. Las ciudades invisibles

\section{Cristina Pérez Andrés}

Subdirección General de Epidemiologia. Promoción y Educación para la Salud. Dirección General de Salud Pública. Ministerio de Sanidad y Consumo.

Como ya se viene experimentando, la edición electrónica de la información significa nuevas posibilidades y desafíos para la comunicación científica en dos sentidos, el de hacer accesibles las publicaciones científicas de un país al resto de ellos y el de tener acceso él mismo, con las ventajas que ofrece internet, a las revistas editadas fuera de sus fronteras, lo que es particularmente interesante para los países en vías de desarrollo.

En relación con ello, entre los días 29 de noviembre y 3 de diciembre de 1999, se han celebrado en Washington, en la sede de la Organización Panamericana de la Salud (OPS), la I Reunión de coordinación regional de la Biblioteca Virtual en Saludy VII Reunión del Sistema Latinoamericano y del Caribe de Información en Ciencias de la Salud. Durante las mismas se ha procedido a la inauguración de la sección de salud pública en la red SciELO (Scientific Electronic Library on Line), la cual es una de las fuentes de información de la Biblioteca Virtual en Salud (BVS) de BIREME. Esta sección de salud pública se inaugura con cinco revistas: Cadernos de Saúde Pública, Revista de Saúde Pública, Revista Española de Salud Pública, Revista Panamericana de Salud Pública y Salud Pública de México. Los editores de las mismas han asistido a dicha reunión, junto con el director de la revista Gaceta Sanitaria, que también está invitada a participar en SciELO. A ellas se irán sumando otras revistas en el futuro.

La Biblioteca Virtual cn Salud (BVS) es la iniciativa de la OPS para la cooperación técnica entre los países de la Región de Latinoamérica y el Caribe, y está concebida como una red de fuentes de información que opera en internet. Su objetivo es proporcionar un acceso equitativo a la información científica sobre salud. La propuesta de la BVS fue presentada por la Biblioteca Regional de Medicina para la Región de Latinoamérica y el Caribe (BIREME), en la VI Reunión del sistema Latinoamericano y del Caribe de información en Ciencias de la Salud, que se realizó en San José, Costa Rica, durante el IV congreso Panamericano de Información en Ciencias de la Salud en marzo de 1998.

Las fuentes de información de la BVS están clasificadas en seis tipos de recursos:

Bases de datos clásicas y servicios relacionados (entre ellas LILACS y el servicio SCAD para el acceso a documentos completos).

Publicaciones electrónicas (entre ellas las revistas cientificas incluidas en SciELO).

Fuentes de información de apoyo a la educación y a la toma de decisión (para el desarrollo y operación de colecciones electrónicas de textos y multimedias que operan con 
libre acceso en internet en los centros de enseñanza).

Difusión selectiva de información (para dar conocimiento de nuevas fuentes de información, a través del correo electrónico y la página web de la BVS).

Comunicación en la BVS (listas de discusión, teleconferencias, entrevistas en línea,...).

Los componentes integradores de la BVS (el vocabulario DeCS, descriptores en ciencias de la salud; el localizador de información en salud LIS, que opera los catálogos que referencian las fuentes de información interna y externas al espacio de la BVS; y las metodologías comunes utilizadas por las instituciones productoras e intermediarias de la información).

El DeCS (Descriptores en Ciencias de la Salud) se encuentra disponible en una base de datos en tres idiomas - español, portugués e inglés-. Su naturaleza, en cuanto a terminología y estructura es la misma que la del MeSH (Medical Subject Headings) de la National Library of Medicine, lo que permite su participación, con el vocabulario en portugués y español, en el lenguaje unificado para búsqueda en salud, UMLS (Unified Medical Languaje System) de la National Library on Medicine (NLM). El DeCS contiene más de 25.000 entradas, incluyendo los términos procedentes del MeSH y los términos agregados por BIREME. El campo de la salud pública contiene más de 6.000 entradas e incluye áreas como administración de scrvicios de salud, y reforma del sector sanitario, área de ciencias ambientales, salud ambiental, desastres naturales o causados por el hombre, etcétera.

Las revistas científicas se irán progresivamente incorporando en la BVS utilizando la metodología SciELO, que ofrece recursos no sólo para la publicación sino también para la evaluación de las publicaciones cientílicas que participan en su red. El modelo SciELO es producto de un proyecto conjunto entre FAPESP, BIREME y los editores científicos. Entre marzo de 1997 y mayo de 1998 se realizó un proyecto piloto. A partir de junio de 1998, pasó a operar regularmente y se constituyó progresivamente en un modelo de publicación de revistas científicas, inicialmente para Brasil que, posteriormente, se amplió a toda la región de América Latina y el Caribe, y en el que en la actualidad participa España.
SciELO tiene tres componentes: El primero es la metodología, el segundo, las bibliotecas científicas electrónicas en línea, siendo una de ellas SciELO-Salud Pública; el tercero es el desarrollo de acuerdos de cooperación entre los sujetos de la comunicación científica, con el fin de difundir el modelo SciELO.

El objetivo es que en el futuro el crecimiento en los diferentes países del modelo SciELO, dé lugar a una red de sitios SciELO.

La metodología SciELO permite la búsqueda bibliográfica por autor, título, resumen y palabras clave, así como el establecimiento de un control del acceso a las revistas, lo que permite el cálculo de indicadores bibliométricos, incluyendo el factor de impacto basado en las citaciones, de manera igual a los realizados por el Institute for Scientific Information (ISI), permitiéndose con ello la evaluación de las revistas de ciencias de la salud incluidas en su red, tanto a nivel nacional como internacional.

La selección de una revista científica para ser incluida en SciELO conlleva la utilización, en su proceso editorial, de los criterios de calidad aceptados internacionalmente (como la revisión por pares) lo que promueve, también, la mejora de la calidad de las revistas y el reconocimiento de las mismas.

España ha participado en la $I$ Reunión de coordinación regional de la Biblioteca Virtual en $\mathrm{Sa}$ lud y VII Reunión del sistema Latinoamericano y del Caribe de Información en ciencias de la salud de dos formas: con la asistencia de los editores de la Revista Española de Salud Pública, que ya cstá disponible en SciELO, y de Gaceta Sanitaria, y con la intervención del director de la Biblioteca Nacional de Ciencias de la Salud, Perspectivas del desarrollo de la Red Iberoamericana de Información en Ciencias de la salud, todo ello, como resultado de la cooperación entre España y la Región de Latinoamérica y el Caribe para el intercambio de la información científica y técnica en el campo de las ciencias de la salud, que se desarrolla al amparo de un Convenio de Colaboración firmado entre la OPS-BIREME y el Instituto de Salud Carlos III del Ministerio de Sanidad y Consumo español, y por el que la Biblioteca Nacional de Ciencias de la Salud del Instituto, se constituye como Centro Coordinador de BIREME para SciELO en España.

La dirección electrónica para acceder a la Biblioteca Virtual en Salud es: http://www.bireme.br/bvs. Para acceder a SciELO-Salud Pública, 
la dirección en internet es la siguiente: http://www.scielosp.org. Tras entrar en ésta, se puede elegir entre las opciones específicas de cada una de las revistas incluidas, o bien entre las opciones generales, que son la de «búsqueda»: por materias, por autores y por artículos; y la de «informes», entre los que se encuentran dos tipos: «uso del sitio» y «citas». En el primero se obtienen estadísticas sobre el acceso a las revistas, a los ejemplares, y a los artículos. La elección de la entrada «citas» conduce a informes estadísticos de las citas de las revistas, separados en: datos procedentes de revistas, vida media de las citas, revistas citadas y revistas que citan. Dentro de cada una de ellas se puede seguir eligiendo diferentes opciones, según le interese al usuario.

Consideramos que la inclusión de la Revista Española de Salud Pública en la red SciELO supone el reconocimiento de la misma por parte de organismos nacionales e internacionales, así como la oferta que la propia revista hace a los lectores hispanohablantes de todo el mundo de acceder a la información que sobre ciencias de la salud contiene. Por ambos aspectos, celebramos su elección para formar parte de SciELO, así como la iniciativa, por parte de BIREME, de hacer realidad la Biblioteca Virtual en Salud. 